\title{
A Rapid and Green Method for Solvent-Free Synthesis of 1,8-Dioxodecahydroacridines Using Tetrabutylammonium Hexatungstate as a Reusable Heterogeneous Catalyst
}

\author{
Abolghasem DAVOODNIA*, Atefeh ZARE-BIDAKI, Hossein BEHMADI \\ Department of Chemistry, Mashhad Branch, Islamic Azad University, Mashhad, Iran
}

\begin{abstract}
Tetrabutylammonium hexatungstate, $[\mathrm{TBA}]_{2}\left[\mathrm{~W}_{6} \mathrm{O}_{19}\right]$, has been used as an efficient, inexpensive, and recyclable green catalyst for the one-pot three-component synthesis of 1,8-dioxodecahydroacridines by the reaction of dimedone with aromatic or aliphatic aldehydes in the presence of a nitrogen source (ammonium acetate or aromatic amines) under neat conditions. There are several advantages to the current process over the standard procedures available in the literature, including shorter reaction times (7-14 min), higher yields, facile work-up, and minimal environmental impact. Furthermore, the catalyst can be conveniently recovered and reused.
\end{abstract}

Key words: 1,8-dioxodecahydroacridine; solvent-free condition; tetrabutylammonium hexatungstate

CLC number: O643 Document code: A

Received 12 July 2012. Accepted 21 August 2012.

*Corresponding author.Tel: +98-511-8435000; Fax:+98-511-8424020; E-mail: adavoodnia@mshdiau.ac.ir, adavoodnia@yahoo.com

This work was supported by Islamic Azad University, Mashhad Branch.

English edition available online at Elsevier ScienceDirect (http://www.sciencedirect.com/science/journal/18722067).

1,4-Dihydropyridines (1,4-DHPs) have been the subject of considerable attention because of their wide range of pharmaceutical and biological properties, including antitubercular, antibacterial, antihypertensive, anticancer, and anti-inflammatory effects [1-5]. 1,4-DHPs are also commercially used as calcium channel blockers for the treatment of cardiovascular diseases, including hypertension [6,7]. Furthermore, dimeric 4-aryl-1,4-DHPs have been shown to act as HIV-1 protease inhibitors [8,9]. 1,8-Dioxodecahydroacridines and their derivatives are polyfunctionalized 1,4-DHP derivatives and have received less attention than other 1,4-DHP derivatives. The most straightforward synthesis of these compounds involves the three-component cyclocondensation of 1,3-cyclohexanedione or 5,5-dimethyl-1,3-cyclohexanedione (dimedone) with aromatic aldehydes and ammonium acetate or amines in the presence of a catalyst such as [Hmim]TFA [10], $\mathrm{B}\left(\mathrm{C}_{6} \mathrm{~F}_{5}\right)_{3}$ [11], a Brønsted acidic imidazolium salt [12], $\mathrm{Zn}(\mathrm{OAc})_{2}$ [13], proline [14], Amberlyst-15 [15], $\mathrm{CeCl}_{3} \cdot 7 \mathrm{H}_{2} \mathrm{O}$ [16], silica-bonded S-sulfonic acid (SBSSA) [17], and silica-bonded $N$-propyl sulfamic acid (SBNPSA) [18]. These compounds have also been synthesized using the classical Hantzsch procedure [19] and by the reaction of aldoximes with dimedone under microwave irradiation and conventional heating conditions [20]. Although each of these individual methods has their own merits, with the exception of the microwave irradiation procedure they all require relatively long reaction times $(1-7 \mathrm{~h})$. Furthermore, some of these procedures suffer other disadvantages, including the requirement for an expensive catalyst or the use of an excess of catalyst. To avoid these limitations and to improve the reaction conditions available for the synthesis of 1,8-dioxodecahydroacridines, the discovery of new methodologies using new heterogeneous and reusable catalysts is still in demand.

The development of heterogeneous catalysts and how they affect specific transformations in chemical synthesis has become a major area of research. The potential advantages of these materials over homogeneous systems, in terms of their simplified recovery and reusability, could potentially allow for the development of environmentally benign chemical procedures in both academic and industrial settings. Catalysts of this type have the potential to make the processes in which they are applied cleaner, safer, higher-yielding, and relatively inexpensive [21-25]. During the course of our recent studies directed towards the development of practical and environmentally friendly procedures for the synthesis of organic compounds using reusable catalysts [26-34], we investigated the application of the isopolytungstate, tetrabutylammonium hexatungstate $[\mathrm{TBA}]_{2}\left[\mathrm{~W}_{6} \mathrm{O}_{19}\right]$, as a catalyst for a series of organic transformations. This new reusable heterogeneous catalyst performed well and showed a high level of catalytic activity in the Knoevenagel condensation [35] and Biginelli [36] reactions, as well as in the synthesis of bis-coumarins [37]. This fact prompted us to investigate the catalytic activity of this material in the syn- 
thesis of 1,8-dioxodecahydroacridines.

\section{Experimental}

\subsection{Synthesis of tetrabutylammonium hexatungstate $[\mathrm{TBA}]_{2}\left[\mathrm{~W}_{6} \mathbf{O}_{19}\right]$}

A mixture of sodium tungstate dihydrate, $\mathrm{Na}_{2} \mathrm{WO}_{4} \cdot 2 \mathrm{H}_{2} \mathrm{O}$ $(99 \%, 33 \mathrm{~g}, 0.1 \mathrm{~mol})$, acetic anhydride $(40 \mathrm{ml})$, and $\mathrm{N}, \mathrm{N}$-dimethylformamide (DMF, $30 \mathrm{ml}$ ) was heated at $100^{\circ} \mathrm{C}$ for $3 \mathrm{~h}$ to obtain a white cream. A solution of acetic anhydride $(20 \mathrm{ml})$ and $12 \mathrm{~mol} / \mathrm{L} \mathrm{HCl}(18 \mathrm{ml})$ in DMF $(50 \mathrm{ml})$ was then added in a drop-wise manner over a period of time with stirring, and the resulting mixture was filtered to remove the undissolved white solids. A solution of tetrabutylammonium bromide $(15.1 \mathrm{~g}, 0.047 \mathrm{~mol})$ in methanol $(50 \mathrm{ml})$ was then added to the filtrate with rapid stirring to give a white precipitate, and the resulting suspension was stirred for $5 \mathrm{~min}$ and the product subsequently collected by filtration. Recrystallization from a minimum amount of hot dimethyl sulfoxide (DMSO) gave the product as colorless diamond-shaped crystals [38].

\subsection{General procedure for the synthesis of 1,8-dioxodecahydroacridines catalyzed by $[\mathrm{TBA}]_{2}\left[\mathrm{~W}_{6} \mathbf{O}_{19}\right]$}

A mixture of dimedone 1 ( $2 \mathrm{mmol})$, aromatic or aliphatic aldehyde $2(1 \mathrm{mmol})$, ammonium acetate or aromatic amine $3(1 \mathrm{mmol})$, and $[\mathrm{TBA}]_{2}\left[\mathrm{~W}_{6} \mathrm{O}_{19}\right](0.04 \mathrm{~g}, 2 \mathrm{~mol} \%$ based on the aldehyde) was heated in an oil bath at $120{ }^{\circ} \mathrm{C}$ for $7-14$ $\min$. The reaction process was monitored by TLC. Upon completion of the transformation, the reaction mixture was cooled to room temperature and hot chloroform was added. This resulted in the precipitation of the catalyst, which was collected by filtration. The filtrate was then collected and distilled to dryness to give the crude product, which was recrystallized from a mixture of $\mathrm{EtOH}$ and $\mathrm{H}_{2} \mathrm{O}$ to give compounds $\mathbf{4 a - 4 q}$ in high yields (Scheme 1). Melting points of the compounds were recorded on a Stuart SMP3 melting point apparatus. The IR spectra were obtained using a Tensor 27 Bruker spectrophotometer from $\mathrm{KBr}$ disks. The ${ }^{1} \mathrm{H}$ NMR (400 and $500 \mathrm{MHz}$ ) spectra were recorded with Bruker 400 and 500 spectrometers.

\section{Results and discussion}

The $[\mathrm{TBA}]_{2}\left[\mathrm{~W}_{6} \mathrm{O}_{19}\right]$ catalyst was prepared according to the method reported by Fournier [38]. Our efforts to develop an efficient and environmentally benign methodology for the synthesis of 1,8-dioxodecahydroacridines focused initially on the three-component cyclocondensation of dimedone with 4-chlorobenzaldehyde and ammonium acetate as a model reaction. Thus, a catalytic amount of $[\mathrm{TBA}]_{2}\left[\mathrm{~W}_{6} \mathrm{O}_{19}\right]$ was added to a mixture of dimedone, 4-chlorobenzaldehyde, and ammonium acetate in different solvents and under solvent-free conditions (Table 1). Pleasingly, we discovered that the reaction was efficiently catalyzed by $[\mathrm{TBA}]_{2}\left[\mathrm{~W}_{6} \mathrm{O}_{19}\right]$ under solvent-free conditions at an elevated temperature, providing a high yield of product $\mathbf{4 d}$. The reaction conditions were then optimized by conducting the reac-

Table 1 Synthesis of compound $\mathbf{4 d}$ in the presence of the $[\mathrm{TBA}]_{2}\left[\mathrm{~W}_{6} \mathrm{O}_{19}\right]$ catalyst under different reaction conditions

\begin{tabular}{|c|c|c|c|c|c|}
\hline Entry & $\begin{array}{c}\text { Catalyst } \\
\text { (g) }\end{array}$ & Solvent & $\begin{array}{c}\text { Temperature } \\
\left({ }^{\circ} \mathrm{C}\right) \\
\end{array}$ & $\begin{array}{l}\text { Time } \\
(\mathrm{min})\end{array}$ & $\begin{array}{c}\text { Yield }^{*} \\
(\%) \\
\end{array}$ \\
\hline 1 & - & - & 120 & 60 & 35 \\
\hline 2 & 0.015 & - & 80 & 25 & 54 \\
\hline 3 & 0.015 & - & 100 & 20 & 60 \\
\hline 4 & 0.015 & - & 120 & 15 & 75 \\
\hline 5 & 0.015 & - & 130 & 15 & 75 \\
\hline 6 & 0.030 & - & 80 & 20 & 65 \\
\hline 7 & 0.030 & - & 100 & 15 & 70 \\
\hline 8 & 0.030 & - & 120 & 10 & 85 \\
\hline 9 & 0.030 & - & 130 & 10 & 84 \\
\hline 10 & 0.040 & - & 80 & 15 & 68 \\
\hline 11 & 0.040 & - & 100 & 12 & 80 \\
\hline 12 & 0.040 & - & 120 & 7 & 93 \\
\hline 13 & 0.040 & - & 130 & 7 & 93 \\
\hline 14 & 0.050 & - & 80 & 15 & 65 \\
\hline 15 & 0.050 & - & 100 & 12 & 74 \\
\hline 16 & 0.050 & - & 120 & 10 & 85 \\
\hline 17 & 0.050 & - & 130 & 10 & 85 \\
\hline 18 & 0.040 & $\mathrm{H}_{2} \mathrm{O}$ & reflux & 120 & 50 \\
\hline 19 & 0.040 & EtOH & reflux & 120 & 87 \\
\hline 20 & 0.040 & $\mathrm{MeOH}$ & reflux & 120 & 80 \\
\hline 21 & 0.040 & $\mathrm{CHCl}_{3}$ & reflux & 120 & 65 \\
\hline 22 & 0.040 & $\mathrm{CH}_{3} \mathrm{CN}$ & reflux & 120 & 70 \\
\hline
\end{tabular}

Reaction conditions: dimedone $2 \mathrm{mmol}$, 4-chlorobenzaldehyde $1 \mathrm{mmol}$, ammonium acetate $1 \mathrm{mmol}$. "Isolated yields.

4a: $\mathrm{R}_{1}=\mathrm{C}_{6} \mathrm{H}_{5}, \mathrm{R}_{2}=\mathrm{H}$

4b: $\mathrm{R}_{1}=4-\mathrm{BrC}_{6} \mathrm{H}_{4}, \mathrm{R}_{2}=\mathrm{H}$

4c: $\mathrm{R}_{1}=2-\mathrm{ClC}_{6} \mathrm{H}_{4}, \mathrm{R}_{2}=\mathrm{H}$

4d: $\mathrm{R}_{1}=4-\mathrm{ClC}_{6} \mathrm{H}_{4}, \mathrm{R}_{2}=\mathrm{H}$

4e: $\mathrm{R}_{1}=4-\mathrm{MeC}_{6} \mathrm{H}_{4}, \mathrm{R}_{2}=\mathrm{H}$

4f: $\mathrm{R}_{1}=3,4-(\mathrm{MeO})_{2} \mathrm{C}_{6} \mathrm{H}_{3}, \mathrm{R}_{2}=\mathrm{H}$

4g: $\mathrm{R}_{1}=4-\mathrm{Me}_{2} \mathrm{NC}_{6} \mathrm{H}_{4}, \mathrm{R}_{2}=\mathrm{H}$

4h: $\mathrm{R}_{1}=3-\mathrm{O}_{2} \mathrm{NC}_{6} \mathrm{H}_{4}, \mathrm{R}_{2}=\mathrm{H}$

4i: $\mathrm{R}_{1}=4-\mathrm{O}_{2} \mathrm{NC}_{6} \mathrm{H}_{4}, \mathrm{R}_{2}=\mathrm{H}$
$4 j: \mathrm{R}_{1}=\mathrm{C}_{6} \mathrm{H}_{5}, \mathrm{R}_{2}=\mathrm{C}_{6} \mathrm{H}_{5}$ 4k: $\mathrm{R}_{1}=4-\mathrm{ClC}_{6} \mathrm{H}_{4}, \mathrm{R}_{2}=4-\mathrm{MeC}_{6} \mathrm{H}_{4}$ 4I: $\mathrm{R}_{1}=4-\mathrm{MeC}_{6} \mathrm{H}_{4}, \mathrm{R}_{2}=4-\mathrm{MeC}_{6} \mathrm{H}_{4}$ 4m: $\mathrm{R}_{1}=3-\mathrm{O}_{2} \mathrm{NC}_{6} \mathrm{H}_{4}, \mathrm{R}_{2}=4-\mathrm{MeC}_{6} \mathrm{H}_{4}$ 4n: $\mathrm{R}_{1}=4-\mathrm{ClC}_{6} \mathrm{H}_{4}, \mathrm{R}_{2}=4-\mathrm{MeOC}_{6} \mathrm{H}_{4}$ $\mathrm{N}$
$\mathrm{R}$
$\mathrm{R}_{2}$ $\mathbf{4 a}-\mathbf{4 q}$ 4o: $\mathrm{R}_{1}=4-\mathrm{MeC}_{6} \mathrm{H}_{4}, \mathrm{R}_{2}=4-\mathrm{MeOC}_{6} \mathrm{H}_{4}$

4p: $\mathrm{R}_{1}=\mathrm{Et}, \mathrm{R}_{2}=\mathrm{H}$

4q: $\mathrm{R}_{1}=n-\operatorname{Pr}, \mathrm{R}_{2}=\mathrm{H}$

Scheme 1. Synthesis of 1,8-dioxodecahydroacridines catalyzed by $[\mathrm{TBA}]_{2}\left[\mathrm{~W}_{6} \mathrm{O}_{19}\right]$. 
tion at different temperatures and employing different loadings of the catalyst. The results are summarized in Table 1. A low yield of the product was only obtained in the absence of the catalyst at $120{ }^{\circ} \mathrm{C}$ following a $60 \mathrm{~min}$ reaction time (Table 1 , entry 1 ), indicating that the catalyst was necessary to the reaction. The best result was obtained when the reaction was conducted at $120^{\circ} \mathrm{C}$ in the presence of $0.040 \mathrm{~g}(2$ $\mathrm{mol} \%$ ) of the $[\mathrm{TBA}]_{2}\left[\mathrm{~W}_{6} \mathrm{O}_{19}\right]$ catalyst (Table 1, entry 12 ).

To evaluate the scope of this catalytic transformation, the optimized reaction conditions were subsequently applied to the reaction of dimedone 1 with a variety of different aromatic and aliphatic aldehydes $\mathbf{2}$ in the presence of one of two nitrogen sources, including ammonium acetate or an aromatic amine 3 (Table 2). A wide range of aromatic and aliphatic aldehydes bearing either electron-donating or elec- tron-withdrawing substituents reacted successfully with dimedone and ammonium acetate or aromatic amines to give the corresponding 1,8-dioxodecahydroacridines products in high yields over short reaction times. When an aromatic amine substituted with an electron-withdrawing group was used, however, 1,8-dioxooctahydroxanthenes [39] were formed as the products (Table 2, entries 18-20). According to Shen's report [12], aromatic amines substituted with an electron-withdrawing group are not nucleophilic enough to produce 1,8-dioxodecahydroacridines.

To further evaluate the overall utility of the current methodology, we compared our results with those of the other methods reported for the synthesis of 1,8-dioxodecahydroacridines. This comparison is shown in Table 3. It is clear from the data that our method reduces the

Table 2 Synthesis of the 1,8-dioxodecahydroacridines $\mathbf{4 a}-\mathbf{4 q}$ using the $[\mathrm{TBA}]_{2}\left[\mathrm{~W}_{6} \mathrm{O}_{19}\right]$ catalyst

\begin{tabular}{|c|c|c|c|c|c|}
\hline \multirow{2}{*}{ Entry } & \multirow{2}{*}{ Product $^{\mathrm{a}}$} & \multirow{2}{*}{ Time (min) } & \multirow{2}{*}{ Yield $^{\mathrm{b}}(\%)$} & \multicolumn{2}{|c|}{ Melting point $\left({ }^{\circ} \mathrm{C}\right)$} \\
\hline & & & & Found & Reported \\
\hline 1 & $4 a$ & 7 & 90 & $288-290$ & $258-260[16]$ \\
\hline 2 & $4 b$ & 7 & 90 & $314-316$ & $312-315$ [16] \\
\hline 3 & $4 c$ & 10 & 88 & $225-227$ & $221-223$ [20] \\
\hline 4 & $4 d$ & 7 & 93 & $298-299$ & $298-300[16]$ \\
\hline 5 & $4 e$ & 8 & 90 & $322-324$ & $318-320[16]$ \\
\hline 6 & $4 f$ & 14 & 84 & $260-263$ & $258-260[20]$ \\
\hline 7 & $4 g$ & 14 & 84 & $265-267$ & $264-266$ [20] \\
\hline 8 & $4 h$ & 10 & 87 & $302-304$ & 294-296 [16] \\
\hline 9 & $4 i$ & 10 & 94 & $284-286$ & $288-289$ [16] \\
\hline 10 & $4 \mathbf{j}$ & 12 & 85 & $257-259$ & $254-256[15]$ \\
\hline 11 & $4 k$ & 10 & 89 & $275-278$ & $269-271$ [12] \\
\hline 12 & 41 & 14 & 85 & $297-300$ & $292-294$ [12] \\
\hline 13 & $4 \mathrm{~m}$ & 13 & 88 & $280-282$ & $283-284$ [12] \\
\hline 14 & $4 n$ & 10 & 89 & $250-253$ & $251-252$ [12] \\
\hline 15 & 40 & 10 & 87 & $236-238$ & $238-241$ [12] \\
\hline 16 & $4 p$ & 13 & 86 & $258-260$ & $282-283$ [20] \\
\hline 17 & $4 q$ & 13 & 85 & $257-258$ & $286-287$ [20] \\
\hline 18 & & 10 & 88 & 204-207 & 204-205 [39] \\
\hline 19 & & 10 & 85 & $228-230$ & $230-233$ [39] \\
\hline 20 & & 10 & 87 & $172-174$ & $170-173$ [39] \\
\hline
\end{tabular}

Reaction conditions: dimedone $2 \mathrm{mmol}$, aldehyde $1 \mathrm{mmol}$, ammonium acetate or aromatic amine $1 \mathrm{mmol},[\mathrm{TBA}]_{2}\left[\mathrm{~W}_{6} \mathrm{O}_{19}\right] 0.04 \mathrm{~g}(2 \mathrm{~mol} \%), 120{ }^{\circ} \mathrm{C}$, solvent-free.

${ }^{a}$ All the products were characterized according to their IR spectral data and a comparison of their melting points with those of authentic samples. The structures of some products were also confirmed by ${ }^{1} \mathrm{H}$ NMR analysis.

${ }^{\mathrm{b}}$ Isolated yields. 
Table 3 Comparison of the efficiencies of different catalysts for the synthesis of 1,8-dioxodecahydroacridines

\begin{tabular}{|c|c|c|c|c|c|}
\hline Catalyst & Solvent & Temperature $\left({ }^{\circ} \mathrm{C}\right)$ & Time (min) & Yield (\%) & Ref. \\
\hline [Hmim]TFA & - & 80 & $240-420$ & $78-89$ & [10] \\
\hline$\left[\mathrm{B}\left(\mathrm{C}_{6} \mathrm{~F}_{5}\right)_{3}\right]$ & - & r.t. & $90-180$ & $75-90$ & {$[11]$} \\
\hline Brønsted acidic imidazolium salts & $\mathrm{H}_{2} \mathrm{O}$ & reflux & 240 & $79-91$ & [12] \\
\hline $\mathrm{Zn}(\mathrm{OAc})_{2}$ & $\mathrm{H}_{2} \mathrm{O}$ & reflux & $120-180$ & $84-94$ & [13] \\
\hline Proline & $\mathrm{H}_{2} \mathrm{O} / \mathrm{EtOH}$ & 65 & $300-360$ & $73-88$ & [14] \\
\hline Amberlyst-15 & $\mathrm{CH}_{3} \mathrm{CN}$ & reflux & $270-390$ & $81-95$ & [15] \\
\hline $\mathrm{CeCl}_{3} \cdot 7 \mathrm{H}_{2} \mathrm{O}$ & {$[\mathrm{bmim}]\left[\mathrm{BF}_{4}\right]$} & 100 & 180 & $82-94$ & [16] \\
\hline SBSSA & $\mathrm{EtOH}$ & reflux & $60-270$ & $84-96$ & [17] \\
\hline SBNPSA & $\mathrm{EtOH}$ & reflux & $120-300$ & $86-93$ & [18] \\
\hline$[\mathrm{TBA}]_{2}\left[\mathrm{~W}_{6} \mathrm{O}_{19}\right]$ & - & 120 & $7-14$ & 84-94 & this work \\
\hline
\end{tabular}

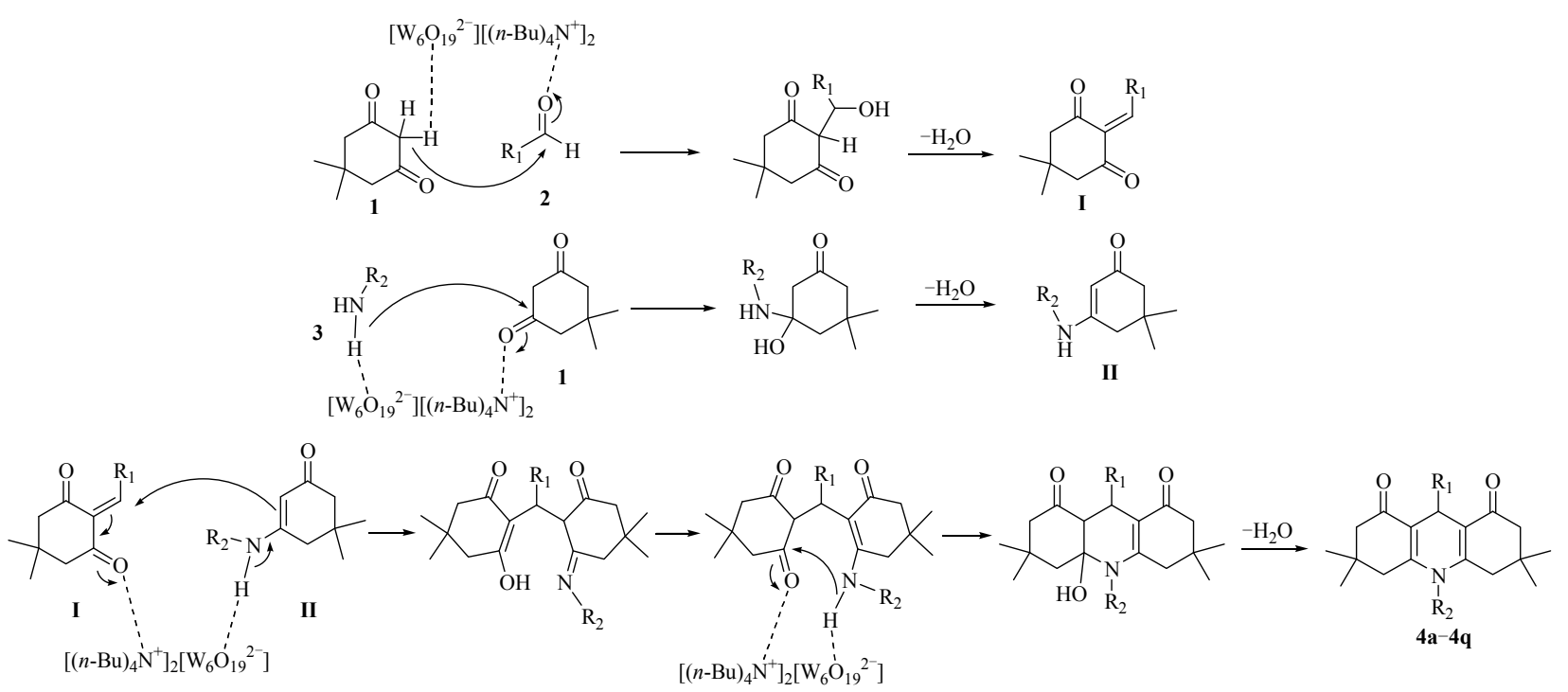

Scheme 2. Plausible mechanism for the formation of 1,8-dioxodecahydroacridines in the presence of the $[\mathrm{TBA}]_{2}\left[\mathrm{~W}_{6} \mathrm{O}_{19}\right]$ catalyst.

reaction times significantly and provides higher yields of the products.

In the interests of green chemistry and developing an environmentally benign process, the reusability of the catalyst was explored using the model reaction system under the optimized conditions. The catalyst itself could be readily recovered from the reaction mixture according to the procedure outlined in the experimental section. The separated catalyst was washed with cold ethanol and subsequently dried at $60^{\circ} \mathrm{C}$ under vacuum for $1 \mathrm{~h}$ before being reused in a similar reaction. The catalyst could be used at least three times without significant reduction in its activity ( $93 \%$ yield for first use, $93 \%$ for second use, and $92 \%$ for third use).

A plausible mechanism for the formation of the 1,8-dioxodecahydroacridine products using $[\mathrm{TBA}]_{2}\left[\mathrm{~W}_{6} \mathrm{O}_{19}\right]$ as a catalyst has been depicted in Scheme 2. Based on our previous reports [35,37], we were aware that $[\mathrm{TBA}]_{2}\left[\mathrm{~W}_{6} \mathrm{O}_{19}\right]$ can play a dual role. Thus, we propose that the tetrabutylammonium ion $\left[(n-\mathrm{Bu})_{4} \mathrm{~N}^{+}\right]$induces the polarization of the carbonyl groups, whereas the terminal oxygen atoms or the bridging oxygen atom in the poly- oxometalate anion, $\mathrm{W}_{6} \mathrm{O}_{19}{ }^{2-}$, are slightly basic and can promote the necessary reactions. The $[\mathrm{TBA}]_{2}\left[\mathrm{~W}_{6} \mathrm{O}_{19}\right]$ can therefore activate the reactants and the intermediates in this reaction. As shown in Scheme 2, we propose that $[\mathrm{TBA}]_{2}\left[\mathrm{~W}_{6} \mathrm{O}_{19}\right]$ facilitates the formation of the intermediates I and II that subsequently react together to give the final products $\mathbf{4 a}-\mathbf{4 q}$.

\section{Conclusions}

The isopolytungstate, $[\mathrm{TBA}]_{2}\left[\mathrm{~W}_{6} \mathrm{O}_{19}\right]$, showed high catalytic activity in the synthesis of 1,8-dioxodecahydroacridines via the one-pot three-component reaction of dimedone with aromatic or aliphatic aldehydes and ammonium acetate or aromatic amines under solvent-free conditions. This procedure offers several advantages over the other techniques available in the literature, including much shorter reaction times, higher yields, facile workup, and the absence of any hazardous organic solvents, which makes it a useful and attractive protocol for the synthesis of these compounds. Furthermore, the catalyst could be recycled after a simple 
work-up, and used at least three more times without significant reduction in its catalytic activity. The procedure is also advantageous in the sense that it is a solvent-free reaction and therefore operates under environmentally friendly conditions.

\section{References}

1 Sirisha K, Bikshapathi D, Achaiah G, Reddy V M. Eur J Med Chem, 2011, 46: 1564

2 Solanki M J, Vachharajani P R, Dubal G G, Shah V H. Int J ChemTech Res, 2011, 3: 1139

3 Ogawa T, Nakato A, Tsuchida K, Hatayama K. Chem Pharm Bull, 1993, 41: 108

4 Sirisha K, Achaiah G, Reddy V M. Arch Pharm, 2010, 343: 342

5 Jain S M, Kant R, Devi S, Dahr K L, Singh S, Bani S, Singh G B. Indian J Chem Sect B, 1990, 29: 95

6 Furuta T, Shibata S, Kodama I, Yamada K. J Cardiovasc Pharmacol, 1983, 5: 836

7 Laurent S, Brisac A M, Champeroux P, Lacolley P, Huguet F, Legrand M, Lucet B, Tsoucaris D, Briand V, Schmitt H. Fundam Clin Pharm, 1989, 3: 47

8 Hilgeroth A, Billich A, Lilie H. Eur J Med Chem, 2001, 36: 367

9 Hilgeroth A, Dressler C, Neuhoff S, Spahn-Langguth H, Langguth P. Pharmazie, 2000, 55: 784

10 Dabiri M, Baghbanzadeh M, Arzroomchilar E. Catal Commun, 2008, 9: 939

11 Chandrasekhar S, Rao Y S, Sreelakshmi L, Mahipal B, Reddy C R. Synthesis, 2008: 1737

12 Shen W, Wang L M, Tian H, Tang J, Yu J J. J Fluorine Chem, 2009, 130: 522

13 Balalaie S, Chadegani F, Darviche F, Bijanzadeh H R. Chin J Chem, 2009, 27: 1953

14 Venkatesan K, Pujari S S, Srinivasan K V. Synth Commun, 2009, 39: 228

15 Das B, Thirupathi P, Mahender I, Reddy V S, Rao Y K. J Mol Catal A, 2006, 247: 233

16 Fan X, Li Y, Zhang X, Qu G, Wang J. Heteroat Chem, 2007, 18: 786

17 Niknam K, Panahi F, Saberi D, Mohagheghnejad M. J Heterocyclic Chem, 2010, 47: 292
18 Rashedian F, Saberib D, Niknam K. J Chin Chem Soc, 2010, 57: 998

19 Martin N, Quinteiro M, Seoane C, Soto J L, Mora A, Suarez M, Ochoa E, Morales A, del Bosque J R. J Heterocycl Chem, 1995, 32: 235

20 Tu S, Miao C, Gao Y, Fang F, Zhuang Q, Feng Y, Shi D. Synlett, 2004: 255

21 Davoodnia A, Allameh S, Fazli S, Tavakoli-Hoseini N. Chem Pap, 2011, 65: 714

22 Gerard V S, Notheisz F. Heterogeneous Catalysis in Organic Chemistry. San Diego: Elsevier, 2000

23 Aoyama T, Takido T, Kodomari M. Synlett, 2004: 2307

24 Emrani A, Davoodnia A, Tavakoli-Hoseini N. Bull Korean Chem Soc, 2011, 32: 2385

25 Davoodnia A, Tavakoli-Nishaburi A, Tavakoli-Hoseini N. Bull Korean Chem Soc, 2011, 32: 635

26 Moghaddas M, Davoodnia A, Heravi M M, Tavakoli-Hoseini N. Chin J Catal, 2012, 33: 706

27 Tavakoli-Hoseini N, Davoodnia A. Asian J Chem, 2010, 22: 7197

28 Heravi M M, Saeedi M, Karimi N, Zakeri M, Beheshtiha Y S, Davoodnia A. Synth Commun, 2010, 40: 523

29 Seifi N, Zahedi-Niaki M H, Reza Barzegari M, Davoodnia A, Zhiani R, Kaju A A. J Mol Catal A, 2006, 260: 77

30 Davoodnia A. Asian J Chem, 2010, 22: 1595

31 Norouzi H, Davoodnia A, Bakavoli M, Zeinali-Dastmalbaf M, Tavakoli-Hoseini N, Ebrahimi M. Bull Korean Chem Soc, 2011, 32: 2311

32 Zeinali-Dastmalbaf M, Davoodnia A, Heravi M M, Tavakoli-Hoseini N, Khojastehnezhad A, Zamani H A. Bull Korean Chem Soc, 2011, 32: 656

33 Tavakoli-Hoseini N, Davoodnia A. Chin J Chem, 2011, 29: 203

34 Khojastehnezhad A, Davoodnia A, Bakavoli M, Tavakoli-Hoseini N, Zeinali-Dastmalbaf M. Chin J Chem, 2011, 29: 297

35 Davoodnia A. Synth React Inorg Met-Org Nano-Met Chem, 2012, 42: 1022

36 Mohammadzadeh-Dehsorkh N, Davoodnia A, Tavakoli-Hoseini N, Moghaddas M. Synth React Inorg Met-Org Nano-Met Chem, 2011, 41: 1135

37 Davoodnia A. Bull Korean Chem Soc, 2011, 32: 4286

38 Fournier M. Inorg Synth, 1990, 27: 80

39 Song G, Wang B, Luo H, Yang L. Catal Commun, 2007, 8: 673 